\title{
Indium sulfide and ternary In-S-O nanowires for optoelectronic applications
}

\author{
J. Bartolomé, D. Maestre, A. Cremades and J. Piqueras
}

Department of Materials Physics, Facultad de Ciencias Físicas, Universidad Complutense de Madrid, Madrid, 28040, Spain

Indium sulfide $\left(\operatorname{In}_{2} \mathrm{~S}_{3}\right)$ is a promising semiconductor material for window layers in solar cell devices and other optoelectronic applications as it presents a direct band gap around $2.0 \mathrm{eV}$ at room temperature, and large photosensitivity and photoconductivity. The presence of several polymorphic structures depending on the processing parameters is also of interest to tailor the required material properties for different applications. It is currently being investigated for high efficiency solar cell based on $\mathrm{CuInS}_{2}-\mathrm{In}_{2} \mathrm{~S}_{3}$ heterostructures, replacing CdS layers [1]. Few studies have been reported on nanostructured $\operatorname{In}_{2} \mathrm{~S}_{3}$ grown by several methods $[2,3]$.

This work reports on the growth, by an evaporation-solidification method [4] and the study of structural and optical properties of indium sulfide (IS) nanowires and of indium-sulfur-oxide (ISO) micro- and nanostructures, as a function of their dimensions, morphology or composition. The analysis of the morphology, as well as the effect of the $\mathrm{S}$ to In ratio on the luminescence of the ISO micro- and nanostructures, have been performed by means of imaging and spectral cathodoluminescence and EDX-SEM techniques. X-ray photoelectron spectroscopy (XPS) and scanning photoelectron microscopy (SPEM) measurements are used to study the valence band and the core-level of the elements, and the local surface chemical variations among the samples. Nanowires of about 70-120 $\mathrm{nm}$ and submicrometer structures consisting in bunched nanowires of IS have been grown at temperatures between 900 and $1000^{\circ} \mathrm{C}$ (figure 2a). The partial oxidation of IS leads to triangular terraced surfaces, rods, complex branched structures and pyramids by increasing the oxygen content (figure 2b). Luminescence spectra measured by cathodoluminescence in the SEM show new luminescence emission bands at $1.45 \mathrm{eV}$ and $1.24 \mathrm{eV}$ related to the presence of $\mathrm{S}$ in the samples. The characteristic emission band of $\operatorname{In}_{2} \mathrm{O}_{3}$ around $1,9 \mathrm{eV}$ is also detected.

\section{References}

1. B. Asenjo, et al., Solar Energy Materials \& Solar Cells 87: 647

2. M. F. Cansizoglu, et al., ACS Nano 4:733

3. D. K. Nagesha, et al. J. Phys. Chem. B 105:7490

4. D. A. Magdas, et al., Appl. Phys. Lett. 88:113107 


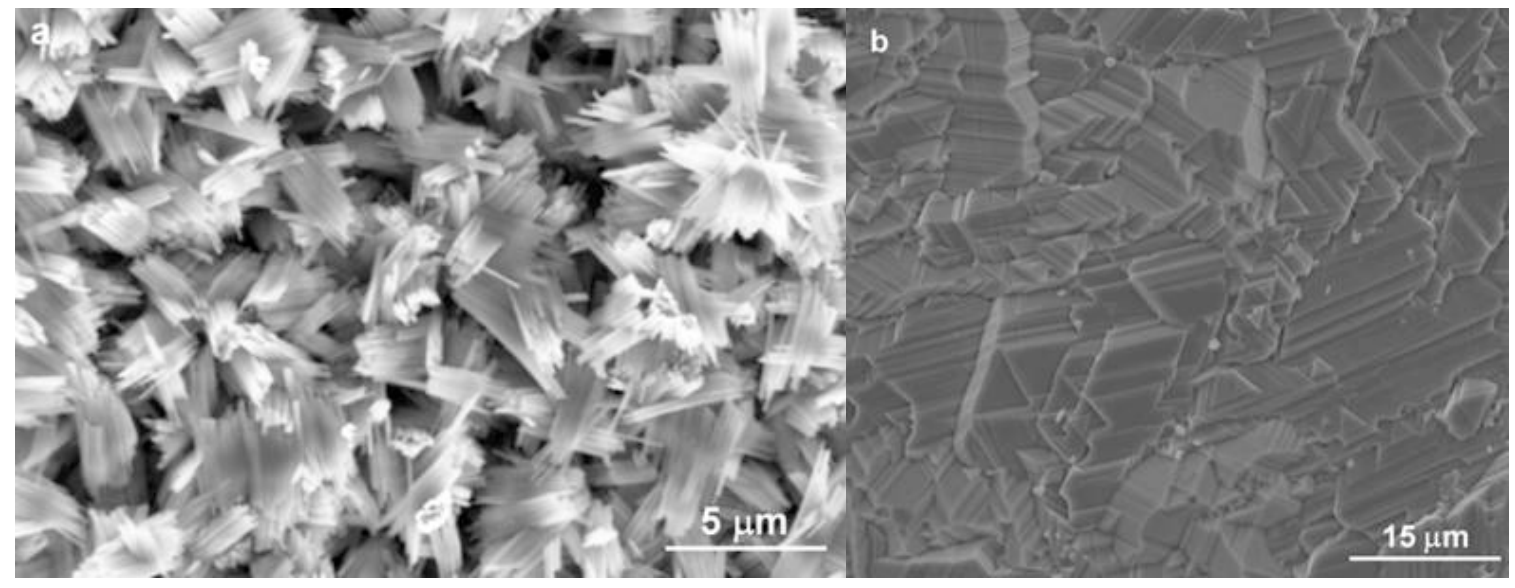

Figure 1. (a) Rods grouped forming complex branched structures and (b) triangular terrace surfaces.

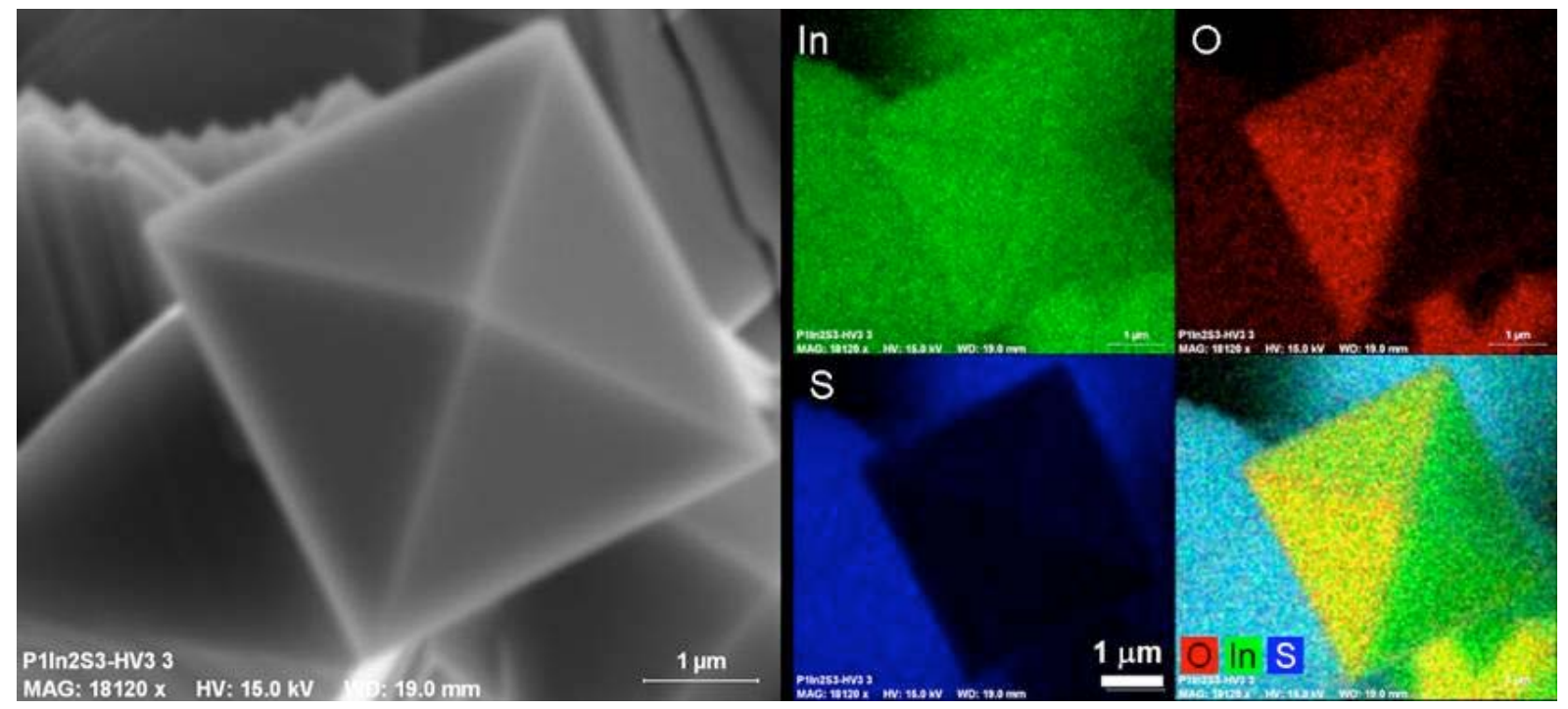

Figure 2. Secondary electron and EDX mappings of the sample surface. An inhomogeneous distribution of sulfur is observed. 